\title{
Handgrip strength accuracy as discriminator of functional independence in centenarian women
}

\section{Acurácia da força de preensão manual como discriminador da independência funcional em centenárias}

\author{
Artur Rodrigues Fortunato \\ (1D) https://orcid.org/0000-0001-6727-7723 \\ Raquel Ester Lima da Silva ${ }^{2}$ \\ (D) https://orcid.org/0000-0002-2368-5319 \\ Giovana Zarpellon Mazo ${ }^{1}$ \\ (D) https://orcid.org/ 0000-0002-7813-5592
}

\begin{abstract}
The aim of this study was to verify and compare handgrip strength (HS) with activities of the daily living (ADL) and to identify the cutoff point of HGS in the prediction of independence in ADL of centenarians. Twenty-four centenarians with mean age of $101.67 \pm$ 2.80 years participated in the study. Subjects were asked about marital status, schooling (years), diseases, hearing difficulties and activities of the daily living (Katz scale), to classify functional independence. Handgrip strength of the right hand (HSR) and left hand (HSL) (mean of the three measures of each hand) was evaluated by means of manual dynamometer. The U Mann Whitney test was applied to compare HSR and HSL with functions of ADL. To identify the cutoff point (sensitivity and specificity) of the right and left HGS of centenarians in the prediction of independence in functions of ADL, the Received Operating Characteristic (ROC) Curves were used. The following cutoff points were used: $11 \mathrm{Kgf}$ for HSR (sensitivity $=66.7 \%$, specificity $=100 \%$, ROC curve $=0.778$ ) and $9 \mathrm{Kgf}$ for HSL (sensitivity $=66.7 \%$, specificity $=77.8 \%$, curve $\mathrm{ROC}=0.730$ ) to predict independence in performing the "bathing" function; 11 Kgf for HSR for the "continence" function (sensitivity $=83.3 \%$, specificity $=66.7 \%$, ROC curve $=0.712$ ); and $9 \mathrm{Kgf}$ for HSL for "transfer" function (sensitivity $=80 \%$, specificity $=71.4 \%$, ROC curve $=0.786$ ). For these functions, sensitivity and specificity presented values greater than $66 \%$. On all these functions, sensitivity showed values higher than $46 \%$ and specificity $77 \%$. Minimum HSR is required to perform functions of ADL independently. The best HSR cutoff point to predict independence of subjects differs according to functions of activities of the daily living and hand evaluated.
\end{abstract}

Key words: Centenarians; Independence; Physical

Resumo - Objetivou-se verificar e comparar a força de preensão manual (FPM) com as funçôes das atividades de vida diária (AVD's) e identificar o ponto de corte dessa força na predição da independência nas AVD's em centenárias. Participaram do estudo 24 centenárias, com média de idade de 101,67+2,80 anos. Foram aplicadas nas idosas, em forma de entrevista, questöes sobre o estado civil, escolaridade (anos), doenças, dificuldade auditiva e as atividades de vida diária (escala de Katz), para classificar a independência funcional. Foi avaliada a força da preensão manual direita (FPMD) e esquerda (FPME) (média entreas três medidas de cada mão) das centenárias por meio do dinamômetro manual. Foi aplicado o teste UMann Whitney para comparar a FPMD e FPME com as funçöes das AVD's. Para identificar o ponto de corte (sensibilidade especificidade) da FPM direita e esquerda das centenárias na predição da independência nas funçôes das AVD's, foi utilizado as Curvas ROC (Received Operating Characteristic). O ponto de corte de $11 \mathrm{Kg}$ fpara a FPMD (sensibilidade $=66,7 \%$; especificidade=100\%; curva $R O C=0,778$ ) e $9 \mathrm{Kg}$ f para a FPME (sensibilidade=66,7\%; especificidade=77,8\%; curva $R O C=0,730$ ) para predizem independência na realização da função "tomar banbo"; de $11 \mathrm{Kg}$ fpara a FPMD para a função "continência" ( sensibilidade $=83,3 \%$; especificidade $=66,7 \%$; curva $R O C=0,712$ ); $e$ de 9 Kgf para a FPME para a "transferência" (sensibilidade=80\%; especificidade=71,4\%; curva $R O C=0,786)$. Para estas funçôes a sensibilidade e a especificidade apresentaram valores maiores de 66\%. É necessário um nível minimo de FPM para executar as funções da AVD com independência. O melhor ponto de corte da FPM para predizer a independência de centenárias, difere de acordo com as funções de vida diária e a mão avaliada.

Palavras-chave: Aptidão física; Centenários; Dependência.
1 Santa Catarina State University. Department of Health and Sports Science. Florianópolis, SC. Brazil.

2 University of Porto. Faculty of Sports. Research Center on Physical Activity, Health and Leisure. Porto. Portugal.

Received: June 04, 2018 Accepted: January 19, 2019

How to cite this article Fortunato A, Silva REL, Mazo GZ. Handgrip strength accuracy as discriminator of functional independence in centenarian women. Rev Bras Cineantropom Desempenho Hum 2020, 22:e57447. DOI: http://dx.doi. org/10.1590/1980-0037.2020v22e57447

Copyright: This work is licensed under a Creative Commons Attribution 4.0 International License. 


\section{INTRODUCTION}

The increase in life expectancy of populations is a worldwide trend ${ }^{1}$. Better health conditions and reduced disabilities increase the life expectancy of populations ${ }^{2}$. Between 2010 and 2015, the number of centenarians increased by $50 \%$ approximately in the world ${ }^{1}$. For this population, functional capacity was considered a good survival predictor ${ }^{3}$.

The person is independent when performing activities of the daily living (ADL) without supervision, guidance or assistance ${ }^{4}$. The development and maintenance of this capacity maintain the well-being in this population for healthy aging ${ }^{5}$. Thus, there is a need of knowing the degree of independence for ADL in old age. The human being reaches the peak of functional capacity in adulthood and then starts the functional decline, which is influenced by several factors ${ }^{5}$. One of the factors that can cause this decline in aging is the decrease in muscle strength due to the loss of muscle mass and speed of muscle fiber contraction ${ }^{6}$.

Regarding handgrip strength (HGS), there is an increase in early adulthood, maintenance until middle age and decline from old age; men are on average stronger than women since adolescence; and the decrease in this strength increases with age, reaching prevalence of $23 \%$ in men and $27 \%$ in women at the age of 80 years $^{7}$.

A systematic review study with meta-analysis found that of the 20 studies that investigated muscle strength, most $(\mathrm{n}=13)$ used HGS as a measure of total muscle strength ${ }^{8}$. The evaluation of HGS is recognized as an important tool in the identification of individuals with sarcopenia and frailty ${ }^{7}$ as a measure to verify the functional performance of frail elderly women ${ }^{9}$, a useful tool to identify mobility limitations in individuals aged 65 or over in the community ${ }^{10}$, and a marker of decline in ADL in individuals aged 85 years or older ${ }^{11}$.

Regarding centenarians, a prospective study found that Asian elderly people with high HGS and healthy lifestyle had increased likelihood of reaching 100 years of age ${ }^{12}$. In addition, HGS was associated with better physical function in centenarians ${ }^{13}$. However, there is lack of investigations on HGS, reference values and functional independence in centenarians.

Despite the high and growing number of investigations on the functional health in the elderly ${ }^{4-6}$, studies with populations of centenarians are still scarce. The search for measures and parameters for assessing the functional fitness of this population is relevant in view of the heterogeneity of the aging process. In addition, it is known that minimum handgrip strength (HGS) level is necessary to perform activities of the daily living, thereby demonstrating the importance of assessing HGS as a general indicator of strength and functionality in individuals at very advanced age, as is the case with centenarians.

In this context, assessing the accuracy of HGS as a discriminating factor of functional independence in centenarian women is useful in clinical practice for the prognosis of independence and to assist health profession- 
als in preventing functional dependence and loss of HGS by adopting the practice of physical exercises.

Thus, the aim of this study was to verify and compare handgrip strength (HGS) with functions of activities of the daily living (ADL) and to identify cutoff points for HGS in the prediction of independence in the performance of these functions in centenarian women.

\section{METHOD}

This descriptive research is part of the "SC100: Multidimensional Study

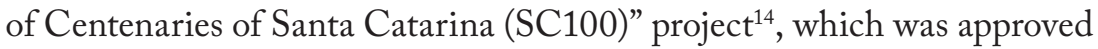
by the Ethics Committee of Research with Human Beings of UDESC, No. 1.468.034 / 2014, under CAAE 21417713.9.0000.0118, and that complies with requirements of the National Health Council under resolution 466/2012.

The study population was composed of 58 centenarians, 41 women and 17 men, living in the metropolitan region of Florianópolis, SC, Brazil. For this study, the inclusion criteria were to be 100 years old or older with supporting document, to be female and to have physical conditions to perform the handgrip strength test. The option for evaluating females was due to the fact that men are stronger in HGS compared to women ${ }^{7}$ and the predominance of women in old age and among the age group of 100 years or older ${ }^{15}$. Thus, the sample consisted of 24 centenarian women.

The data collection instrument is the Multidimensional Assessment Protocol for Centenarian Individuals - PAMIC ${ }^{16}$, which was developed for the SC100 project, prepared by the Gerontology Laboratory (LAGER), Department of Health and Sport Sciences (CEFID), Santa Catarina State University (UDESC). For the present study, the following questions and PAMIC Blocks were applied, according to the following objectives:

- To confirm the age of centenarians: the date of birth was consulted in the supporting document (questions 2, 3 and 6; Block 01- Identification);

- To characterize the sample as to sex (question 4; Block 01- Identification), marital status (question 47; Block 04 - Sociodemographic Information) and diseases (questions 88 to 106; Block 07 - Health Conditions and Life Habits);

- To identify the ear that the individual listens best to direct the interview and verbal stimuli during the execution of the HGS test (question 12; Block 02 - Auditory Evaluation);

- To classify independence for activities of the daily living such as bathing, dressing, using the toilet, transfer, continence and feeding (questions 129 to 134; Block 08 - Functional Capacity Assessment). In this block, the Portuguese version of the Katz Scale of independence in activities of the daily living was used ${ }^{4}$. The authors state that the Katz Scale is based on the assessment of the individual's functional 
dependence or independence when bathing, dressing, using the toilet, transfer, continence and feeding.

- To record the HGS assessment (question 213; Block 16 - Kinanthropometry and Physical Assessment). The HGS test was measured using SAEHAN dynamometer model SH5001 and followed recommendations of the American Society of Hand Therapists ${ }^{17}$.

Data collection took place from March 2015 to March 2017. Prior to data collection, training was carried out to prepare interviewers, according to recommendations of the Interviewer Manual: Application and Analysis of the Multidimensional Evaluation Protocol for Centenarian Individu$\mathrm{als}^{14}$. Subsequently, telephone contact was made with caregiver and / or centenarian, and the invitation to participate in the research was made. Upon acceptance, a date was scheduled for data collection and signature of the Free and Informed Consent Form - TCLE. Subsequently, the ear that the centenarian best listened was identified and the PAMIC ${ }^{16}$ questions were applied to individuals or their caregivers in the form of an interview.

The HGS test followed recommendations of the American Society of Hand Therapists, in which individuals should be comfortably seated with adducted shoulder, elbow flexed at $90^{\circ}$, forearm in neutral position and wrist varying from 0 to $30^{\circ}$ in extension ${ }^{17}$. To perform the test, the evaluator initially presented the equipment to the centenarian to become familiar with the instrument ${ }^{18}$. Subsequently, participants were asked to apply the greatest possible strength. Three measurements were made in each hand, respecting the 20 -second rest interval between each measurement ${ }^{19}$.

Data were organized in the Excel ${ }^{\circledR}$ for Windows software and analyzed using IBM SPSS Statistics version 20.0. In the tabulation of responses, for the analysis of handgrip strength, the highest value among three measures of each hand, right and left, was used. For the analysis of the Katz scale, the sum of responses of centenarians was performed, according to independence and dependence in a given function, according to Lino et al. ${ }^{4}$.

Descriptive analysis was performed, with position and dispersion measures (numerical variables) and absolute and relative frequency (categorical variables). The Shapiro-Wilk test was adopted to verify data normality. The Mann Whitney U test was applied to compare right and left handgrip strength with functions of activities of the daily living. To identify the cutoff point (sensitivity and specificity) of the right and left handgrip strength in the prediction of functional independence and their respective functions, the ROC curves (Received Operating Characteristic) were used. Significance level of 0.05 was adopted.

\section{RESULTS}

Twenty-four centenarian women with mean age of 101.67 (SD = 2.80) years participated in this research. Regarding the characteristics of study participants, the majority are widower (91.7\%), illiterate (45.8\%), with 
hearing difficulties (79.2\%). The main self-reported diseases were systemic arterial hypertension (50\%) and osteoporosis (45.8\%) (Table 1).

Table 1. Characterization of study participants $(n=24)$

\begin{tabular}{|c|c|c|}
\hline Variables & $f$ & $\%$ \\
\hline \multicolumn{3}{|l|}{ Marital status } \\
\hline Single & 02 & 8.3 \\
\hline Widower & 22 & 91.7 \\
\hline \multicolumn{3}{|l|}{ Schooling (years) } \\
\hline Illiterate & 11 & 45.8 \\
\hline From 1 to 8 years & 9 & 37.5 \\
\hline 9 or + years & 4 & 16.7 \\
\hline \multicolumn{3}{|c|}{ Self-reported diseases } \\
\hline \multicolumn{3}{|l|}{ Cardiovascular } \\
\hline Yes & 4 & 16.7 \\
\hline No & 20 & 83.3 \\
\hline \multicolumn{3}{|l|}{ Hypertension } \\
\hline Yes & 12 & 50.0 \\
\hline No & 12 & 50.0 \\
\hline \multicolumn{3}{|l|}{ Diabetes } \\
\hline Yes & 3 & 8.3 \\
\hline No & 22 & 91.7 \\
\hline \multicolumn{3}{|l|}{ Osteoporosis } \\
\hline Yes & 11 & 45.8 \\
\hline No & 13 & 54.2 \\
\hline \multicolumn{3}{|l|}{ Depression } \\
\hline Yes & 4 & 16.7 \\
\hline No & 20 & 83.3 \\
\hline \multicolumn{3}{|l|}{ Hearing difficulties } \\
\hline Yes & 19 & 79.2 \\
\hline No & 5 & 20.8 \\
\hline
\end{tabular}

As shown in Table 2, it was observed that among functions of activities of the daily living (ADL), "feeding" was the one with the highest number of independent centenarians ( $n=23)$. When comparing the right handgrip strength (HGR) and the left handgrip strength (HGL) with functions of ADL, there is a significant difference among independent centenarians for functions "bathing" and HGR ( $p=0.022)$ and HGL ( $p=0.054)$, "transfer" and HGL ( $p=0.042)$ and "continence" and HGL ( $p=0.053)$.

In the analysis of cutoff points for right handgrip strength (RHGS) and left handgrip strength (LHGS) to predict independence in functions of the ADL of centenarian women, $11 \mathrm{Kgf}$ for RHGS (sensitivity $=66.7 \%$ ; specificity $=100 \%$; ROC curve $=0.778$ ) and $9 \mathrm{Kgf}$ for LHGS (sensitivity $=66.7 \%$; specificity $=77.8 \%$; ROC curve $=0.730$ ) were identified to predict independence in performing the "bathing" function; $11 \mathrm{Kgff}$ for RHGS for "continence" function (sensitivity $=83.3 \%$; specificity $=66.7 \%$; ROC curve 
= 0.712); and $9 \mathrm{Kgf}$ for LHGS for "transfer" function (sensitivity = 80\%; specificity $=71.4 \%$; ROC curve $=0.786$ ). For these functions, sensitivity and specificity showed values greater than $66 \%$ (Table 3 and Figure 1).

Table 2. Comparison of right and left handgrip strength of centenarians with classification of functions of activities of the daily living

\begin{tabular}{|c|c|c|c|c|c|}
\hline $\begin{array}{l}\text { Functions } \\
\mathrm{ADL}\end{array}$ & $\begin{array}{l}\text { Classification } \\
\text { (n) }\end{array}$ & $\begin{array}{l}\text { HGR (Kgf) } \\
\text { Mean (SD) }\end{array}$ & $p$-value & $\begin{array}{l}\text { HGL (Kgf) } \\
\text { Mean (SD) }\end{array}$ & $p$-value \\
\hline \multirow[t]{2}{*}{ Bathing } & $I(13)$ & $11.97(4.33)$ & $0.022^{*}$ & $10.48(4.09)$ & $0.054^{*}$ \\
\hline & $\mathrm{D}(11)$ & 8.01 (3.88) & & $6.96(3.37)$ & \\
\hline \multirow[t]{2}{*}{ Dressing } & I (10) & $11.36(4.84)$ & 0.472 & $10.40(4.05)$ & 0.122 \\
\hline & $D(14)$ & $9.29(4.01)$ & & 7.78 (4.93) & \\
\hline \multirow[t]{2}{*}{ Using the toilet } & I (15) & $10.75(4.71)$ & 0.558 & $9.73(4.65)$ & 0.138 \\
\hline & $D(09)$ & $9.16(3.88)$ & & 7.44 (2.62) & \\
\hline \multirow[t]{2}{*}{ Transfer } & I (14) & $11.57(4.61)$ & 0.138 & $10.14(4.77)$ & $0.042^{*}$ \\
\hline & $\mathrm{D}(10)$ & 8.18 (3.36) & & $7.10(2.06)$ & \\
\hline \multirow[t]{2}{*}{ Continence } & I (11) & $12.04(4.53)$ & $0.053^{*}$ & $10.09(3.49)$ & 0.186 \\
\hline & $\mathrm{D}(13)$ & $8.56(3.74)$ & & $7.84(4.43)$ & \\
\hline \multirow{2}{*}{ Feeding } & I (23) & $10.15(4.50)$ & 0.833 & $8.89(4.20)$ & 0.917 \\
\hline & $D(01)$ & $10.33(-)$ & & $8.33(-)$ & \\
\hline
\end{tabular}

Note. RHGS = Right handgrip strength; $\mathrm{LHGS}=$ Left handgrip strength; $A D L=$ Activities of the daily living; I = Independent; $\mathrm{D}=$ Dependent; $\mathrm{n}=$ sample number; $\mathrm{Kgf}=$ Kilogram force; $\mathrm{SD}=$ standard deviation; $p$-value $=$ significance level; ${ }^{*} p<0.05$.

Table 3. Diagnostic accuracy of right and left handgrip strength to predict independence for functions of activities of the daily living in centenarian women

\begin{tabular}{|c|c|c|c|c|c|}
\hline $\begin{array}{l}\text { Strength/ } \\
\text { ADL functions }\end{array}$ & $\begin{array}{l}\text { Cutoff } \\
\text { point }\end{array}$ & $\begin{array}{c}\text { Sens } \\
\%\end{array}$ & $\begin{array}{c}\text { Spe } \\
\%\end{array}$ & $\begin{array}{l}\text { Area under the curve } \\
(95 \% \mathrm{Cl})\end{array}$ & $p$-value \\
\hline \multicolumn{6}{|l|}{ HGR (Kgf) } \\
\hline Bathing & 11 & 66.7 & 100.0 & $\begin{array}{c}0.778 \\
(0.585-0.971)\end{array}$ & $0.005^{\star}$ \\
\hline Dressing & 11 & 50.0 & 78.6 & $\begin{array}{c}0.590 \\
(0.306-0.792)\end{array}$ & 0.460 \\
\hline Use of toilet & 10 & 46.7 & 77.8 & $\begin{array}{c}0.570 \\
(0.468-0.907)\end{array}$ & 0.540 \\
\hline Transfer & 11 & 50.0 & 90.0 & $\begin{array}{c}0.680 \\
(0.485-0.915)\end{array}$ & 0.104 \\
\hline Continence & 11 & 83.3 & 66.7 & $\begin{array}{c}0.712 \\
(0.500-0.925)\end{array}$ & $0.051^{*}$ \\
\hline \multicolumn{6}{|l|}{ HGL(Kgf) } \\
\hline Bathing & 9 & 66.7 & 77.8 & $\begin{array}{c}0.730 \\
(0.529-0.931)\end{array}$ & $0.025^{\star}$ \\
\hline Dressing & 12 & 50.0 & 92.9 & $\begin{array}{c}0.680 \\
(0.364-0.845)\end{array}$ & 0.123 \\
\hline Use of toilet & 12 & 40.0 & 100.0 & $\begin{array}{c}0.680 \\
(0.598-0.964)\end{array}$ & 0.095 \\
\hline Transfer & 9 & 80.0 & 71.4 & $\begin{array}{c}0.786 \\
(0.598-0.973)\end{array}$ & $0.003^{*}$ \\
\hline Continence & 5 & 100.0 & 30.8 & $\begin{array}{c}0.660 \\
(0.464-0.895)\end{array}$ & 0.162 \\
\hline
\end{tabular}

Note. $\mathrm{HGR}=$ Right handgrip strength; $\mathrm{HGL}=$ Left handgrip strength; $\mathrm{ADL}=$ Activities of the daily living; Sens = Sensitivity; Spe = Specificity; $95 \% \mathrm{Cl}=$ Confidence Interval; $\mathrm{Kgf}=$ kilogram force; $p$-value $=$ significance level; ${ }^{*} p<0.05$. 

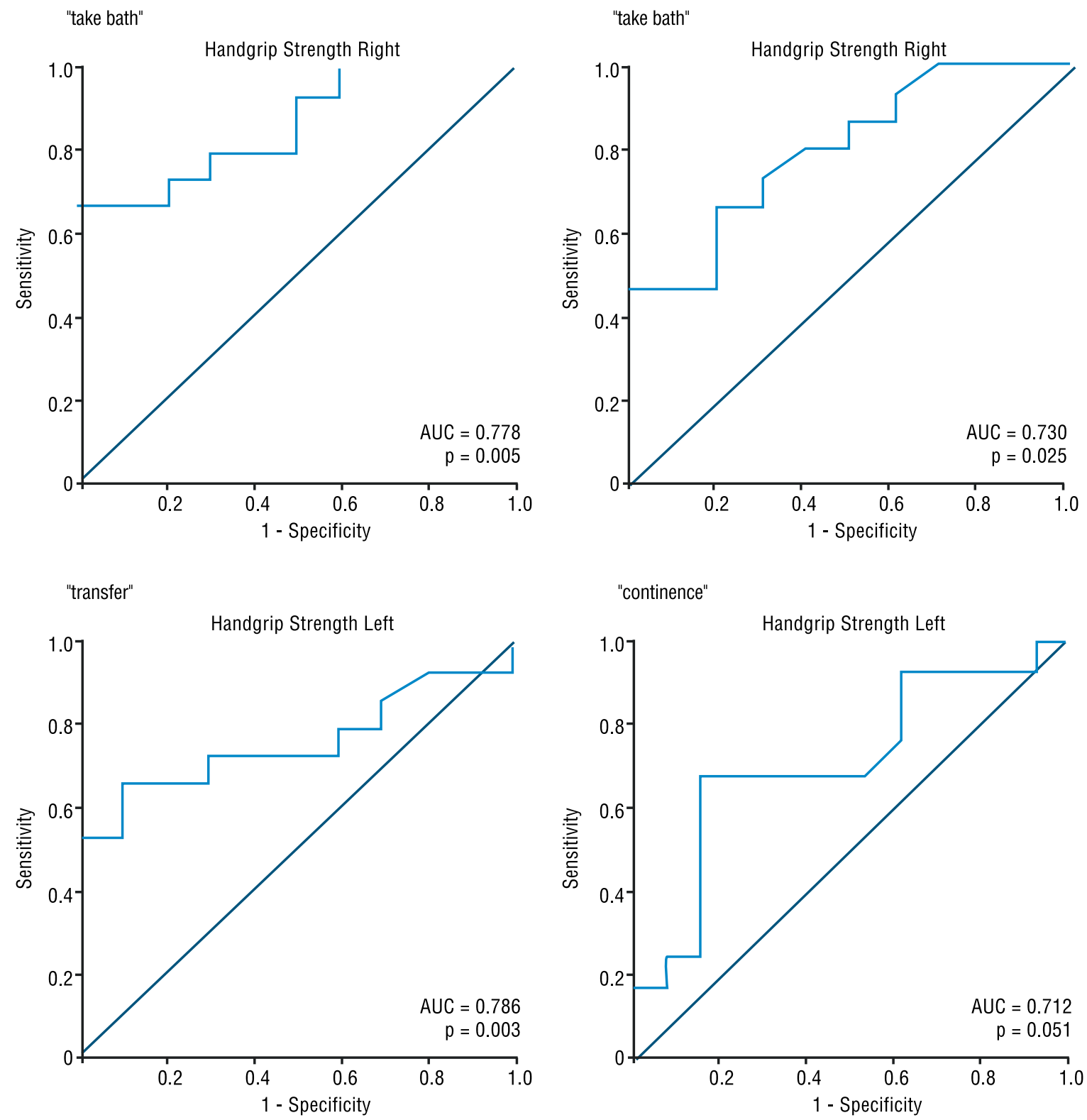

Figure 1. Cutoff point curve of right and left handgrip strength to predict independence in functions of ADL of centenarians. Note. HGS $=$ Handgrip strength.

\section{DISCUSSION}

In the present study, the cutoff point of $11 \mathrm{Kgf}$ of HGR and $9 \mathrm{Kgf}$ of HGL was identified so that centenarians independently perform the "bathing" function, $11 \mathrm{Kgf}$ of HGR for the "continence" function and $9 \mathrm{Kgf}$ of $\mathrm{HGL}$ for the "transfer" function.

Although literature does not present specific HGS reference values for the population of centenarians, studies with elderly people younger than those of the present study have shown the following results: between 28 $\mathrm{Kgf}$ and $29.8 \mathrm{Kgf}$ for men and $18 \mathrm{Kgf}$ and $16.4 \mathrm{Kgf}$ for women aged 75-79 years $^{20}$; below $16 \mathrm{Kgf}$ for individuals aged 65 or over, who have functional limitations ${ }^{21}$; $17.4 \mathrm{Kgf}$ for women and $25.8 \mathrm{Kgf}$ for men as cutoff points 
for functional mobility of elderly people aged 65 or over $^{10}$; and $\leq 14 \mathrm{Kgf}$ for elderly people aged 80-99 years $^{22}$.

Thus, it was observed that HGS values for both hands of centenarians in this study are lower than those presented in above mentioned studies, which can be explained by the decrease in strength with advancing age and lower values among women ${ }^{7,22}$. There is a decrease of $1 \%$ to $2 \%$ per year in skeletal muscle mass after 50 years of age, which influences strength levels ${ }^{23}$.

Studies have found a decrease in muscle strength among centenarians when compared to other ages, for example, with octogenarians $(50 \%$ reduction) and 92-year-old individuals ${ }^{24}$. Regarding HGS of centenarians, a prospective study followed 2,239 Asians aged 56-68 years for 44 years and found that the likelihood of centenarians reaching longevity occurred, among other factors, due to high HGS and healthy lifestyle ${ }^{12}$. Another study followed 11 centenarians with mean age of 101 years for six months and found significantly low HGS values, between $8.5 \mathrm{kgf}$ to $14.5 \mathrm{kgf}$, and that physical health evaluated by HGS was associated with better physical capacity ${ }^{13}$.

Thus, it is observed that with increasing age, HGS decreases ${ }^{12,22,24}$. HGS was assessed in most of the 20 prospective studies analyzed in a review, which reported associations between strength measures and functional decline in the elderly ${ }^{8}$. This relationship could also be observed in a research carried out with sample of elderly people aged 85 years $^{12}$, who found that low handgrip strength predicts accelerated dependence on ADL and cognitive decline in long-lived older adults. In addition, the authors claim that HGS can be a useful tool in geriatric practice to identify older patients at risk of accelerated decline in ADL.

The functions of ADL - feeding, continence, transfer, use the toilet, dressing and bathing, follow a hierarchy of complexity in the individual's performance in self-care activities, where feeding is less complex and bathing has great complexity ${ }^{4}$. Thus, it appears in the present study that the cutoff points of HGR and HGL found can be used as indicators of independence in functions of "bathing", "continence" and "transfer" of centenarian women.

It was also observed that independent centenarians in the "bathing" function presented higher HGS cutoff point for both hands compared to the other functions - continence and transfer, which are less complex. Population-based study with 1,907 Japanese centenarians concluded that health practices play an important role in preserving ADL and good cognitive and psychosocial status after 100 years of age and should be useful to establish an educational program for the very long-lived population ${ }^{25}$. In addition, appropriate strategies that allow these individuals to live longer without serious disabilities are necessary, since HGS, as an indicator of frailty and risk of disability among centenarians, will allow early identification and intervention ${ }^{26}$.

As for the use of HGS as an epidemiological exposure variable for functional capacity, there are indications that it should not be done indiscriminately, but in the case of very old and physically fragile individuals, it is a general indicator of strength and functionality 9 
The limitations of the present study are the sample size and sex. The small number of centenarians is because this very long-lived population group is small compared to others ${ }^{15}$. In addition, the study found only HGS in centenarian women, as this gender is predominant in the elderly population ${ }^{15}$ and because older women have lower strength compared to $\mathrm{men}^{7}$, which can influence functions of activities of the daily living.

One of the strengths of this study is the inclusion of women aged 100 or over, who were able to perform the handgrip test on both hands and who still perform their ADL functions independently or dependently. In addition, the sample is representative of the metropolitan region of Florianópolis, SC, Brazil, considering that the total population of centenarians living in this mesoregion was taken into account, which were 58 centenarians, 41 of whom were women, distributed in 21 municipalities. In Brazil, the 2010 demographic census found 405 centenarians in the state of Santa Catarina, equivalent to 0.65 per 10,000 inhabitants, and the capital, Florianópolis, has 1.14 centenaries per 10,000 inhabitants ${ }^{15}$. In relation to the other age groups of older adults, centenarians are still few in Brazil ${ }^{15}$.

\section{CONCLUSION}

It could be concluded that the best cutoff point for handgrip strength (HGS) to predict functional independence differs according to activities of daily living and the hand that was assessed. Independent centenarians in the "bathing" function presented higher cutoff points for HGS for both hands than for the other functions - continence and transfer - which are less complex. For centenarian women, cutoff points for HGR and HGL can be used as indicators of independence in functions of the daily living "bathing", "continence" and "transfer".

Future studies are needed to determine the cutoff point for HGS for both hands of centenarians, which assess ADL and overall functional capacity, in addition to studies aimed at evaluating modifiable factors for HGS and functional independence.

\section{Acknowledgments}

To all participants of the "SC100: Multidimensional Study of Centenaries of Santa Catarina" project, participants, caregivers and researchers. The CNPq - Pq productivity grant. To the National Council for Technological Development CNPq 201350 / 2015-7. Support from the Research Center on physical activities and health - CIAFEL, Portugal and the "Santander Universidades do Banco Santander Motta" Project.

\section{COMPLIANCE WITH ETHICAL STANDARDS}

\section{Funding}

This research did not receive any specific grant from funding agencies in the public, commercial, or not-for-profit sectors. This study was funded by the authors. 


\section{Ethical approval}

Ethical approval was obtained from the local Human Research Ethics Committee - State University of Santa Catarina and the protocol ( $\mathrm{n}^{\circ}$ 1.468.034/2014, sob o CAAE 21417713.9.0000.0118) was written in acc ordance with the standards set by the Declaration of Helsinki.

\section{Conflict of interest statement}

The authors have no conflict of interests to declare.

\section{Author Contributions}

Conceived and designed the experiments: ARF and GZM Performed the experiments: ARF and GZM. Analyzed the data: ARF, RELS and GZM. Contributed reagents/materials/analysis tools: ARF, RELS and GZM. Wrote the paper: ARF, RELS and GZM.

\section{REFERENCES}

1. Nations U. Annual Population by Age Groups - Both Sexes. [Internet]. Available from: https://population.un.org/wpp/Download/Standard/Population/ (2017).

2. GBD 2013 DALYs and HALE Collaborators. Global, regional, and national disability-adjusted life years (DALYs) for 306 diseases and injuries and healthy lifeexpectancy (HALE) for 188 countries, 1990-2013: quantifying the epidemiological transition. Lancet 2015;386(10009):2145-91.

3. Mossakowska M, Broczek K, Wieczorowska-Tobis K, Klich-Rączka A, Jonas M, Pawlik-Pachucka E, et al. Cognitive performance and functional status are the major factors predicting survival of centenarians in Poland. J Gerontol A Biol Sci Med Sci 2014; 69(10): 1269-1275.

4. Lino VTS, Pereira SRM, Camacho LAB, Ribeiro Filho ST, Buksman S. Adaptação transcultural da Escala de Independência em Atividades da Vida Diária (Escala de Katz). Cad Saúde Pública 2008; 24(1): 103-112.

5. World Health Organization Ws. World report on ageing and health.[Internet]. Available from: https://www.who.int/ageing/publications/world-report-2015/en/ (2015).

6. Takakusaki K. Functional Neuroanatomy for Posture and Gait Control. J Mov Disord 2017; 10: 1-17.

7. Dodds RM, Syddall HE, Cooper R, Benzeval M, Deary IJ, Dennison EM, et al. Grip strength across the life course: normative data from twelve British studies. PLoS One 2014;9(12):e113637.

8. Schaap LA, Koster A, Visser M. Adiposity, muscle mass, and muscle strength in relation to functional decline in older persons. Epidemiol Rev 2013; 35: 51-65.

9. Geraldes AAR, Oliveira ARMd, Albuquerque RB, Carvalho JM, Farinatti PTV. A força de preensão manual é boa preditora do desempenho funcional de idosos frágeis: um estudo correlacional múltiplo. Rev Bras Med Esporte 2008; 14(1): 12-16.

10. Vasconcelos KS, Dias JM, Bastone AC, Vieira RA, Andrade AC, Perracini MR, et al. Handgrip Strength Cutoff Points to Identify Mobility Limitation in Community-dwelling Older People and Associated Factors. J Nutr Health Aging 2016;20(3):306-15.

11. Taekema DG, Gussekloo J, Maier AB, Westendorp RG, Craen AJ. Handgrip strength as a predictor of functional, psychological and social health. A prospective population-based study among the oldest old. Age Ageing 2010;39(3):331-7.

12. Rantanen T, Guralnik JM, Foley D, Masaki K, Leveille S, Curb JD, et al. Midlife hand grip strength as a predictor of old age disability. JAMA 1999; 281(6): 558-560. 
13. Franke B, Faraone SV, Asherson P, Buitelaar J, Bau CH, Ramos-Quiroga JA, et al. The genetics of attention deficit/hyperactivity disorder in adults, a review. Mol Psychiatry 2012; 17(10): 960-987.

14. Mazo GZ. Manual do Entrevistador: Aplicação e Análise do Protocolo de Avaliação Multidimensional do Idoso Centenário [Internet]. Available from:https://drive. google.com/file/d/1US53JWBOaSfQa0sLliqmHCwxbSOelq_V/view. (2018).

15. Brazilian Institute of Geography and Statistics B. IBGE -Censo Demográfico. [Internet]. Available from:https://sidra.ibge.gov.br/Tabela/1378 (2010).

16. Mazo GZ. Protocolo de Avaliação Multidimensional do Idoso Centenário.[Internet]. Available from:https://drive.google.com/file/d/18O8sBJa_L8PCHa3OQzK1uOW1Da95LMK3/view (2017).

17. Richards LG, Olson B, Palmiter-Thomas P. How forearm position affects grip strength. Am J Occup Ther 1996; 50: 133-138.

18. Bellace JV, Healy D, Besser MP, Byron T, Hohman L. Validity of the Dexter Evaluation System's Jamar dynamometer attachment for assessment of hand grip strength in a normal population. J Hand Ther 2000; 13(1): 46-51.

19. Figueiredo I, Sampaio R, Mancini M, Silva FC, Souza MA. Test of grip strength using the Jamar dynamometer. Acta Fisiátrica 2007;14(2): 104-110.

20. Bohannon R, Peolsson A, Massy-Westropp N, Desrosiers J, Bear-Lehman J. Reference values for adult grip strength measured with a Jamar dynamometer: A descriptive meta-analysis. Physiotherapy 2006; 92(1): 11-15.

21. Alley DE, Shardell MD, Peters KW, McLean RR, Dam TT, Kenny AM, et al. Grip strength cutpoints for the identification of clinically relevant weakness. J Gerontol A Biol Sci Med Sci 2014;69(5):559-66.

22. Lenardt MH, Grden CR, Sousa JA, Reche PM, Betiolli SE, Ribeiro DK. Factors associated with loss of handgrip strength in long-lived elderly. Rev Esc Enferm USP 2014; 48(6): 1006-1012.

23. Keller K, Engelhardt M. Strength and muscle mass loss with aging process. Age and strength loss. Muscles Ligaments Tendons J 2013; 3: 346-350.

24. Oksuzyan A, Maier H, McGue M, Vaupel JW, Christensen K. Sex differences in the level and rate of change of physical function and grip strength in the Danish 1905-cohort study. J Aging Health 2010; 22(5): 589-610.

25. Ozaki A, Uchiyama M, Tagaya H, Ohida T, Ogihara R. The Japanese Centenarian Study: autonomy was associated with health practices as well as physical status. J Am Geriatr Soc 2007; 55(1): 95-101.

26. Lam NW, Goh HT, Kamaruzzaman SB, Chin AV, Poi PJ, Tan MP. Normative data for hand grip strength and key pinch strength, stratified by age and gender for a multiethnic Asian population. Singapore Med J 2016; 57(10): 578-584.

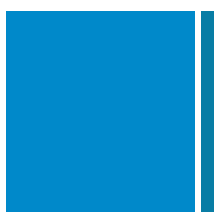

Corresponding author

Giovana Zarpellon Mazo

Santa Catarina State University

College of Health and Sport Science - CEFID

R. Pascoal Simone, 358 - Coqueiros, Florianópolis - SC, 88080-350, Brasil

Email: giovana.mazo@udesc.br 